\title{
A dynamic supramolecular polyurethane network whose mechanical properties are kinetically controlled
}

Article

Accepted Version

Creative Commons: Attribution-Noncommercial-No Derivative Works 4.0

Tang, X., Feula, A., Baker, B. C., Melia, K., Hermida Merino, D., Hamley, I. W., Buckley, C. P., Hayes, W. and Siviour, C. R. (2017) A dynamic supramolecular polyurethane network whose mechanical properties are kinetically controlled. Polymer, 133. pp. 143-150. ISSN 0032-3861 doi: https://doi.org/10.1016/j.polymer.2017.11.005 Available at https://centaur.reading.ac.uk/73966/

It is advisable to refer to the publisher's version if you intend to cite from the work. See Guidance on citing.

To link to this article DOI: http://dx.doi.org/10.1016/j.polymer.2017.11.005

Publisher: Elsevier

All outputs in CentAUR are protected by Intellectual Property Rights law, including copyright law. Copyright and IPR is retained by the creators or other copyright holders. Terms and conditions for use of this material are defined in the End User Agreement. 


\section{CentAUR}

Central Archive at the University of Reading

Reading's research outputs online 


\section{A Dynamic Supramolecular Polyurethane Network whose Mechanical Properties are Kinetically Controlled}

Xuegang Tang ${ }^{a}$, Antonio Feula ${ }^{b}$,Benjamin C. Baker ${ }^{b}$, Kelly Melia $^{b}$, Daniel Hermida Merino $^{c}$, Ian W. Hamley ${ }^{b}$, C. Paul Buckley ${ }^{a}$, Wayne Hayes ${ }^{b}$ and Clive R. Siviour ${ }^{a}$ *

${ }^{a}$ Department of Engineering Science, Oxford University, Parks Road, Oxford, OX1 3PJ, UK

${ }^{\mathrm{b}}$ Department of Chemistry, University of Reading, Whiteknights, Reading, RG6 6AD, UK

c Netherlands Organization for Scientific Research (NWO), DUBBLE@ESRF, 71 Avenue des Martyrs, 38000 Grenoble, France

* Corresponding author, e-mail clive.siviour@eng.ox.ac.uk

\section{Abstract}

We report the synthesis and characterization of a kinetically controlled, thermoreversible supramolecular polyurethane whose mechanical properties depend unusually strongly on the processing history. Materials were prepared by solution casting, quenching and annealing of quenched material, allowing pronounced micro-structural evolution, which leads to rapid increases in modulus as determined by rheological analysis. Tensile tests showed that the quenched material is soft, weak and ductile (shear modulus $\sim 5 \mathrm{MPa}$, elongation $\sim 250 \%$ ), but after annealing, at $70{ }^{\circ} \mathrm{C}$ for one hour, it becomes stiffer, stronger and more brittle $(\sim 20$ MPa, $20 \%$ ). FTIR and NMR spectroscopic analysis, coupled with MDSC and SAXS, were performed to investigate the network's dynamic structural changes. SAXS results suggest the presence of a lamellar structure in the sample when solution cast at high temperature, or annealed. This ordering is unique when compared to structurally-related supramolecular bisurethane and bisurea polymers, and may be the cause of the observed path dependence. These mechanical properties, which can be switched repeatedly by simple thermal treatments, coupled with its adhesion properties as determined from peel and tack tests, make it an excellent candidate as a recyclable material for adhesives and coatings.

Keywords: SPU, Kinetic control, mechanical response 


\section{Introduction}

Supramolecular polymer networks typically comprise low molecular weight oligomers which self-assemble through non-covalent interactions such as metal-ligand coordination bonds, aromatic $\pi-\pi$ interactions, or hydrogen bonds. ${ }^{1-8}$ These self-assembled networks feature mechanical properties of thermoplastics and elastomers, along with significant potential for recycling and self-healing, because of their capability for reversible monomer-to-polymer transitions. Supramolecular polymers have also been designed to yield shape-persistent and highly ordered filaments. ${ }^{9}$ The ability to tune the mechanical properties of supramolecular polymer networks by varying the composition of the oligomer subunits (i.e. recognition motif, polymer backbone molecular weight) is very attractive in materials design. ${ }^{10,11}$ These addressable and tuneable ${ }^{12}$ characteristics are highly desirable in both bulk commodity and value-added applications, such as adhesives, ${ }^{13}$ shape-memory materials, ${ }^{14,15}$ healable coatings, ${ }^{16}$ and impact-resistant structures (for example in mobile electronics). ${ }^{17}$ The majority of supramolecular polymer networks reported to date have had their properties generated under thermodynamic control, as non-covalent interactions are relatively weak and thus assemble/disassemble with low activation energies. However, recently, it has been demonstrated that supramolecular polymerisations can show pathway complexity ${ }^{18-22}$ which has vast functional potential, as they allow, in principle, for more elaborate structural and functional diversity of self-assembled systems. ${ }^{23}$ The most unique feature of such kinetically controlled supramolecular systems is that they provide an opportunity to solve the inherently conflicting challenge of achieving intrinsic processability combined with desirable material properties. ${ }^{24-26}$

In this paper, we report a novel, kinetically controlled thermoreversible supramolecular polyurethane network. The material reported herein simultaneously exhibits inherently good processability, owing to a rapid drop in modulus over a narrow temperature range, and 
tuneable mechanical properties at ambient or near ambient temperatures. Furthermore, in contrast to materials previously reported, these properties can be modified freely and repeatedly by simple thermal treatments (melting, quenching, and annealing processes). This behaviour has not been observed in our previous studies on SPUs: ${ }^{7,27}$ the mechanical response measured in repeated rheological experiments on a single specimen showed no significant change to viscoelastic properties between tests. The switching programme, herein reported, has been established by systematic rheological and mechanical assessment, and the structures producing these unique properties have been investigated through FTIR spectroscopy, MDSC and SAXS, whilst the potential of this material as a pressure-sensitive adhesive has also been explored.

\section{Results and discussion}

The polyurethane material presented in this paper will be shown to have a rich rheological profile coupled with mechanical properties that can be greatly modified through thermal processing. These properties are linked to structural features including microphase separation and dissociation of intermolecular hydrogen bonds at moderate temperatures. Since the endgroup plays an important role in hydrogen bonding and phase separation, this will be discussed first, before moving on to a detailed analysis of the rheological behaviour and associated structural features. Finally, there will be a discussion of data from peel and tack tests on the material. Thus, this paper presents a full picture of the synthesis, chemistry, processing, properties and potential applications of this novel material. Details of the experimental methods are given in the supplementary information. 


\subsection{Synthesis}

The supramolecular polyurethane $\mathbf{1}$ was synthesized using a modification of a two-step protocol. $^{7,10,12,27,28}$ Firstly, the hydrophobic and elastomeric diol KrasolTM HLBH-P2000 was reacted with methylene diphenyl diisocyanate (MDI) at $80{ }^{\circ} \mathrm{C}$ for a period of three hours to generate the isocyanate end-capped prepolymer. Dibenzylamine was then added to the prepolymer to install the receptor end-groups via urea bond formation and afford the desired polyurethane $\mathbf{1}$ in a yield of $89 \%$ (see Figure 1 plus electronic supplementary information (ESM) Figures S1, S2 and S3 for spectroscopic and thermal data). GPC analysis (THF, room temperature) revealed a material with $\mathrm{M}_{\mathrm{n}}$ and $\mathrm{M}_{\mathrm{w}}$ values of 7303 and 14303, respectively.<smiles>CC1(CCCOC(=O)Nc2ccc(Cc3ccc(NC(=O)N(Cc4ccccc4)Cc4ccccc4)cc3)cc2)CCC2(CCCOC(=O)Nc3ccc(Cc4ccc(NC(=O)N(Cc5ccccc5)Cc5ccccc5)cc4)cc3)CCC12</smiles>

Figure 1. Supramolecular polyurethane 1.

\subsection{FTIR and NMR Spectroscopic Analysis}

In order to assess the thermoreversible characteristics of this polymer system, experiments were conducted using NMR and FTIR spectroscopy. Polyurethane $\mathbf{1}$ was probed by variable temperature FTIR spectroscopy to investigate the effect of temperature on the supramolecular network. The FTIR spectra were recorded at temperatures from 30 to $180{ }^{\circ} \mathrm{C}$, see Figure $\mathrm{S} 4$. The absorption band at $c a .1735 \mathrm{~cm}^{-1}$ is characteristic of unbound urethanes. This band increased in intensity as the temperature was elevated, whereas the absorption band at $c a$. $1705 \mathrm{~cm}^{-1}$, consistent with bound urethanes, decreased. Finally, the absorption band at 1740 $\mathrm{cm}^{-1}$ was predominant at a temperature of $150{ }^{\circ} \mathrm{C}$ indicating that almost all of the hydrogen bond interactions were disrupted. 


\subsection{Rheological behaviour}

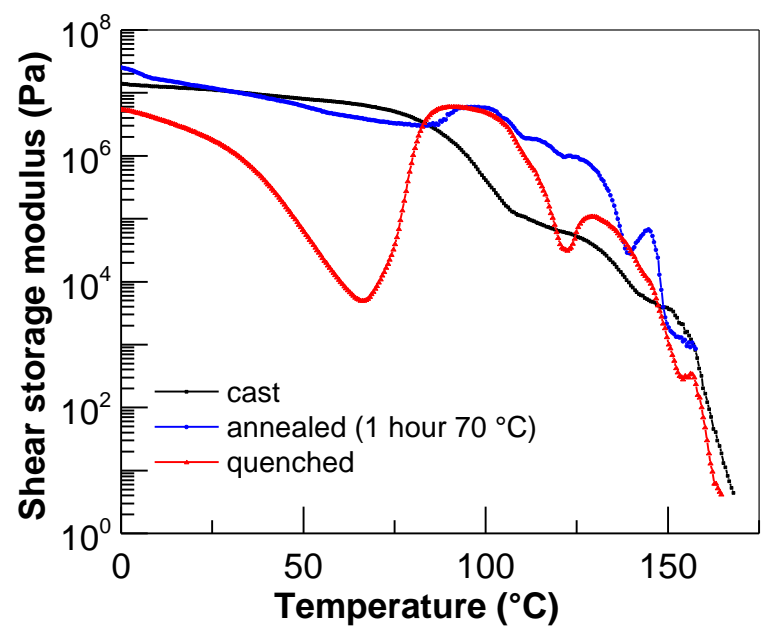

Figure 2. Rheological behaviour of polyurethane 1 with different processing histories, obtained in oscillatory shear at $5 \mathrm{~Hz}$ and an amplitude of $0.1 \%$ with a heating rate of

$$
2^{\circ} \mathrm{C} \min ^{-1}
$$

Dynamic rheological testing was employed to characterise the viscoelastic properties of polyurethane 1. A number of experiments were performed to explore the effects of quenching and annealing on the response. Figure 2 shows a comparison between the temperature dependence of a specimen that was solution cast from THF at $70^{\circ} \mathrm{C}$ over a period of 16 hours, a specimen that, having been cast, was quenched from the molten state at $180{ }^{\circ} \mathrm{C}$ to $20^{\circ} \mathrm{C}$ at an average cooling rate of $15{ }^{\circ} \mathrm{C} \min ^{-1}$, and finally a specimen that has undergone the same quenching process, followed by annealing at $70{ }^{\circ} \mathrm{C}$ for one hour (see also Figure S5 for comparison of data from two annealed specimens and Figure S10 for loss modulus curves from all rheometer experiments described in the paper). At low temperatures (from 0 to 70 ${ }^{\circ} \mathrm{C}$ ), the storage modulus of the cast material exhibits a gradual decrease with increasing temperature. As the temperature is increased further there are three distinct decreases in the storage modulus, between $70{ }^{\circ} \mathrm{C}$ and $105^{\circ} \mathrm{C}$, between $130{ }^{\circ} \mathrm{C}$ and $145^{\circ} \mathrm{C}$, and between $150{ }^{\circ} \mathrm{C}$ and $170^{\circ} \mathrm{C}$, respectively. At temperatures above $170{ }^{\circ} \mathrm{C}$ the rheology approaches that of a low 
viscosity liquid; oscillatory shear experiments could no longer be performed, but viscosity measurements were obtained, and are presented as a function of time in the ESM (Figure S6). These decreases are entirely consistent with the FTIR spectroscopic data presented above which reveal hydrogen bond dissociations with increasing temperature and with SAXS data revealing key structural changes throughout the heating ramp (Figure S7).

The rheological behaviour of the quenched material is very different. At low temperatures, the modulus is lower than that of the cast material, and it shows a significant decrease with increasing temperature, until approximately $65^{\circ} \mathrm{C}$ where there is a rapid increase (over three orders of magnitude) with increasing temperature to $85^{\circ} \mathrm{C}$; this is indicative of significant structural changes in the material. There is a short plateau from $85{ }^{\circ} \mathrm{C}$ to $100{ }^{\circ} \mathrm{C}$, at approximately the same modulus as cast polyurethane $\mathbf{1}$ exhibits at room temperature. Above $100{ }^{\circ} \mathrm{C}$ there are again three sharp drops in storage modulus, the first two of which are followed (as the temperature increases) by a small modulus increase. These are assumed to be associated, again, with the hydrogen bond dissociation.

After quenching followed by annealing at $70{ }^{\circ} \mathrm{C}$ for 1 hour, the behaviour becomes more similar to the cast material, at the lower temperatures. There is still, however, an increase in storage modulus as the temperature increases; although this is weakened and delayed compared to the quenched material, the final modulus is the same. As the temperature is increased further, the drops in modulus seen in with the other materials are observed, but the temperature at which the first drop occurs increases.

Overall, polyurethane $\mathbf{1}$ has both good elevated temperature processability, with a large drop of modulus within a narrow temperature range, and good mechanical properties, with a relatively high modulus, typical of a stiff elastomer, at ambient conditions. However, there are clearly features of the thermomechanical behaviour that warranted further investigation. 


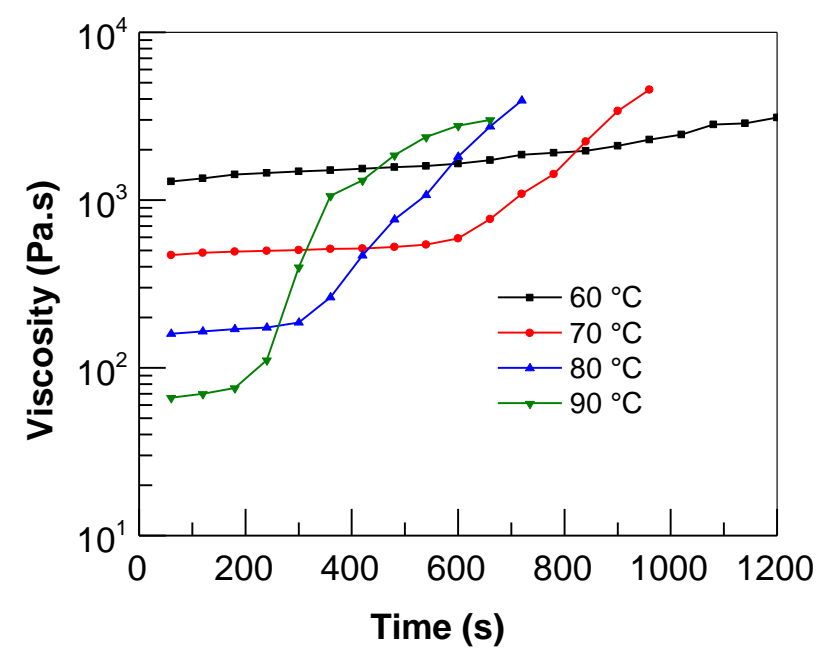

Figure 3. Viscosity $v s$. time profiles for quenched polyurethane $\mathbf{1}$ at different temperatures, obtained at a constant shear rate of $5 \mathrm{~s}^{-1}$.

The first of these features is the increase in modulus with increasing temperature between 65 and $85{ }^{\circ} \mathrm{C}$. This indicates a time-dependent evolution of the structure of the material. To further investigate this phenomenon, the rheological behaviour of quenched polyurethane $\mathbf{1}$ at constant shear rate was measured as a function of time at four different temperatures, see Figure 3. Here it is observed that although the viscosity is reasonably stable at $60{ }^{\circ} \mathrm{C}$, at higher temperatures, a significant increase in viscosity was observed after an initial stable period, these data indicate that there is a time-dependent structural change in the material, which affects the mechanical response, and that this change occurs more rapidly as the temperature increases. Such mechanical variations were also apparent in structural differences seen via SAXS analysis of quenched polyurethane $\mathbf{1}$ held at analogous temperatures to that of Figure 3 (clear distinctions seen between hold at $>80{ }^{\circ} \mathrm{C}$ and those at lower temperatures, see Figure S8). It should be noted that the end of the test was caused by limitations of the instrument, where the maximum viscosity had been reached, and thus the test was aborted automatically. At $90^{\circ} \mathrm{C}$, the increase in viscosity with time is followed by a levelling off, which suggests saturation of the structural evolution. These data are consistent 
with the observations from the temperature sweep in Figure 1: as the temperature is increased from $60^{\circ} \mathrm{C}$ there is a structural evolution which increases the modulus of the material, and which itself occurs more rapidly with increasing temperature until the new structure is fully formed.

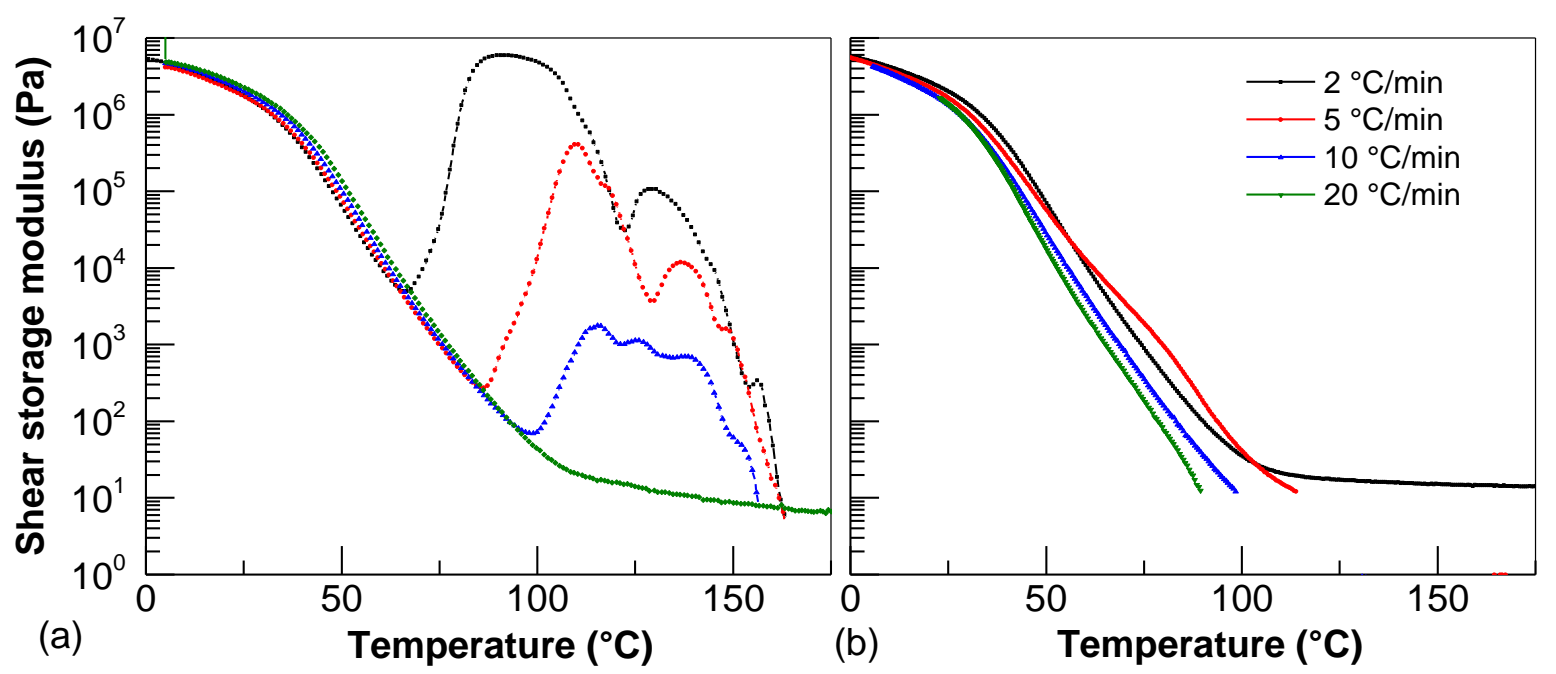

Figure 4. The rheological behaviour of quenched polyurethane 1 at four different (a) heating and (b) cooling rates. All tests performed at an oscillation frequency of $5 \mathrm{~Hz}$ and amplitude of $0.1 \%$.

This behaviour was further investigated through a series of rising and falling temperature sweeps at different heating and cooling rates. Figure 4 shows the temperature dependence of the modulus of quenched specimens tested at four different heating rates and four different cooling rates. The temperature range over which the modulus increases shows a clear dependence on heating rate, Figure $4 \mathrm{a}$, and indeed the increase is not observed at the fastest rate, $20{ }^{\circ} \mathrm{C} \mathrm{min}^{-1}$. These data are consistent with the time dependence of this process: increasing the heating rate shortens the time over which the material is able to undergo the required structural changes, and so a higher temperature is required to drive these changes. At high enough heating rates, this becomes similar to the temperature at which the hydrogen 
bonds begin to disrupt, discussed further below and supported by SAXS measurements taken (ESM Figures S7 and S9a).

In contrast, it is found that different cooling rates have little effect on the rheological response, Figure $4 \mathrm{~b}$. Here, specimens were heated to $180{ }^{\circ} \mathrm{C}$ and held at this temperature for 3 minutes. Above $100{ }^{\circ} \mathrm{C}$ the rheometer was unable to generate reliable data for the faster cooling rates. Below $100{ }^{\circ} \mathrm{C}$ the behaviour was very similar for all the materials. Loss modulus information for all the materials is shown in the ESM (Figure S9b).

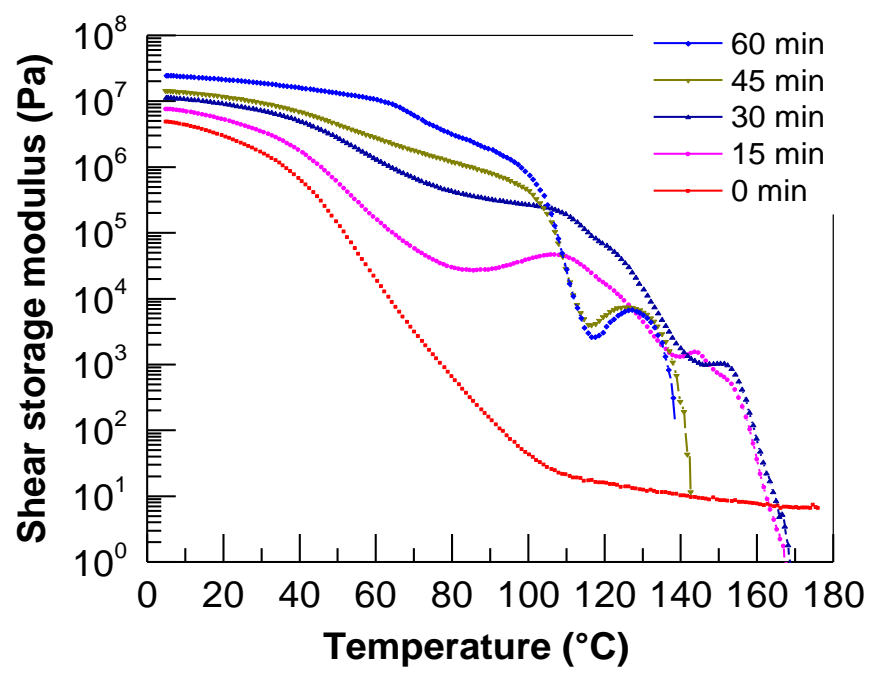

Figure 5. The rheological behaviour of quenched polyurethane 1 after annealing at $70{ }^{\circ} \mathrm{C}$ for different time periods. All experiments performed in oscillatory shear at $5 \mathrm{~Hz}$ and $0.1 \%$ amplitude with a heating rate of $20^{\circ} \mathrm{C} / \mathrm{min}$.

The data presented above, especially those in Figure 3, suggest that the mechanical properties of the material can be controlled through annealing. To investigate the effect of annealing on subsequent material behaviour, a number of specimens were subjected to quenching (from 180 to $20^{\circ} \mathrm{C}$ at $15^{\circ} \mathrm{C} \mathrm{min}-1$, followed by annealing for different periods of time at $70^{\circ} \mathrm{C}$. The specimens were then subjected to rheological analysis and tensile characterisation. The rheological behaviour is presented in Figure 5. The heating rate for these experiments is 
$20{ }^{\circ} \mathrm{C} \min ^{-1}$, chosen to prevent significant further structural evolution taking place between $65^{\circ} \mathrm{C}$ and $85^{\circ} \mathrm{C}$ in these tests. As anticipated, these data show a significant increase of the storage modulus with increasing annealing time. The behaviour above $100{ }^{\circ} \mathrm{C}$ is also worth noting: as the annealing time increases this behaviour becomes increasingly similar to that of the cast material, again exhibiting several sharp drops of storage modulus with increasing temperature.

\subsection{Large strain tensile response}

To further characterize the mechanical performance of polyurethane $\mathbf{1}$ after casting, quenching and annealing, tensile tests were performed. Between four and six experiments were performed on each material; mean stress-strain curves with error bars are shown in Figure 6; corresponding mechanical properties, calculated from the individual stress-strain curves (see Figure S11 in the ESM), are shown in Table 1. In these experiments, the strain was calculated using Digital Image Correlation on images of the specimen surface.

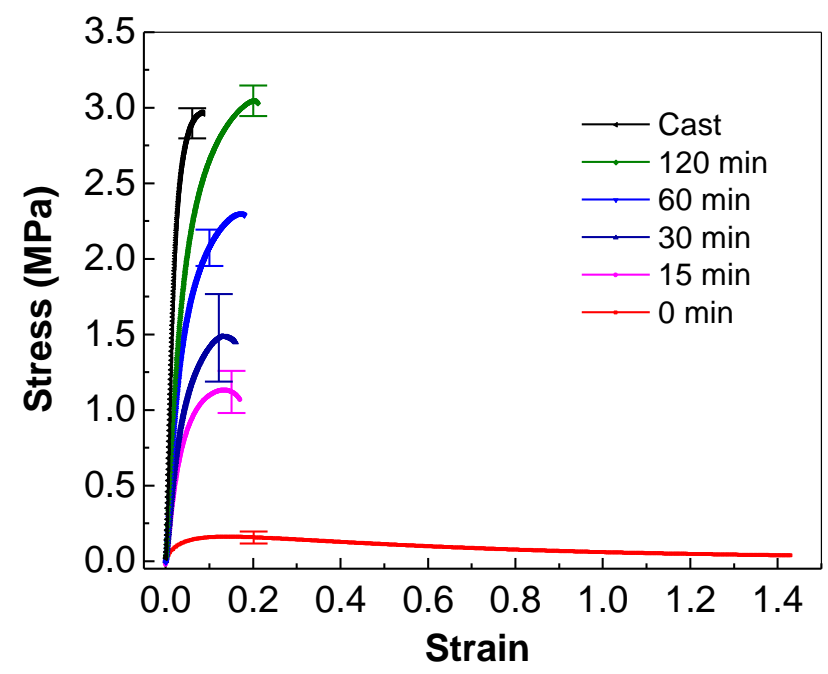

Figure 6. Mean tensile stress-strain curves obtained at $22{ }^{\circ} \mathrm{C}$ for polyurethane 1 quenched then annealed at $70{ }^{\circ} \mathrm{C}$ for different time periods (indicated), and cast polyurethane $\mathbf{1}$. 
The apparent tensile modulus was calculated from the slope of the stress-strain curve between 0 and $3.5 \%$ strain. This is not the true modulus of the material, which is time and strain dependent, but an apparent stiffness representing the behaviour over this period for comparative purposes. The material strength was measured as the largest stress supported by the sample. It is observed that thermal annealing affects the tensile behaviour significantly: two hours annealing at $70{ }^{\circ} \mathrm{C}$ turns quenched polyurethane 1 (QPU) from a low modulus (tensile modulus: $2.45 \mathrm{MPa}$ ), weak (strength: $0.14 \mathrm{MPa}$ ), but ductile (elongation at break: $246 \%$ ) material into a much stiffer (49.1 MPa), stronger (3.08 MPa), but brittle (elongation at break: $23 \%$ ) material. For comparison, the solution cast polyurethane $\mathbf{1}$ presents a similar strength to the 120 minute annealed, but with an elongation at break of only $10 \%$.

\begin{tabular}{cccc}
\hline Sample & Strength (MPa) & $\begin{array}{c}\text { Elongation at } \\
\text { break }(\%)\end{array}$ & $\begin{array}{c}\text { Energy } \\
\text { absorbed (MPa) }\end{array}$ \\
QPU-0min & $0.16 \pm 0.04$ & $246 \pm 78$ & $15.4 \pm 3.2$ \\
QPU-15min & $1.14 \pm 0.14$ & $22.8 \pm 4.1$ & $21.9 \pm 3.1$ \\
QPU-30min & $1.51 \pm 0.29$ & $17.8 \pm 1.0$ & $20.9 \pm 5.4$ \\
QPU-60min & $2.31 \pm 0.12$ & $20.0 \pm 1.9$ & $38.1 \pm 4.3$ \\
QPU-120min & $3.08 \pm 0.10$ & $23.0 \pm 1.8$ & $58.0 \pm 4.8$ \\
Cast PU & $2.81 \pm 0.11$ & $9.7 \pm 2.0$ & $24 \pm 7.0$ \\
& & & \\
\hline
\end{tabular}

Table 1. Mechanical properties from tensile testing for quenched polyurethane $\mathbf{1}$ annealed at $70{ }^{\circ} \mathrm{C}$ for different times (errors shown are standard deviations). 


\subsection{Structural characterisation}

The characterisation data above indicate that polyurethane $\mathbf{1}$ is a kinetically controlled material, whose properties are strongly dependent upon, and can be controlled by, the thermal processing history. To understand the structural changes associated with this behaviour, modulated differential calorimetry (MDSC) and small angle X-ray scattering (SAXS) were performed.

MDSC provides superior sensitivity, resolution and separation of overlapping transitions, than standard DSC. ${ }^{29,30}$ Here, experiments were performed on cast, quenched and quenched then annealed (both one and two hours at $70^{\circ} \mathrm{C}$ ) materials; the results are shown in Figure 7 , where multiple transitions are observed during heating. For the quenched material, three exothermic peaks are evident at temperatures $c a .50{ }^{\circ} \mathrm{C}, 110^{\circ} \mathrm{C}$, and $140{ }^{\circ} \mathrm{C}$, as indicated in the non-reversible heat flow signal in Figure 7c, in addition to three endothermic peaks at $c a$. $100{ }^{\circ} \mathrm{C}, 140{ }^{\circ} \mathrm{C}$, and $170{ }^{\circ} \mathrm{C}$, as indicated in the reversible heat flow signal in Figure $7 \mathrm{~b}$. However, after annealing for two hours the exothermic peak at $50{ }^{\circ} \mathrm{C}$ almost disappears completely, and the endothermic peak at $100{ }^{\circ} \mathrm{C}$ shifts slightly higher to $104{ }^{\circ} \mathrm{C}$; the other exothermic and endothermic peaks at higher temperatures are the same as in the quenched sample. These complex transitions observed in MDSC should correlate to the complex rheological behaviour of polyurethane $\mathbf{1}$, and indeed the transition temperatures match the rheological data very well. The cast material behaves similarly to the quenched, whilst the material annealed for one hour has behaviour intermediate between that for the quenched and two hours annealed samples. These observations are also consistent with the rheological profiles. 

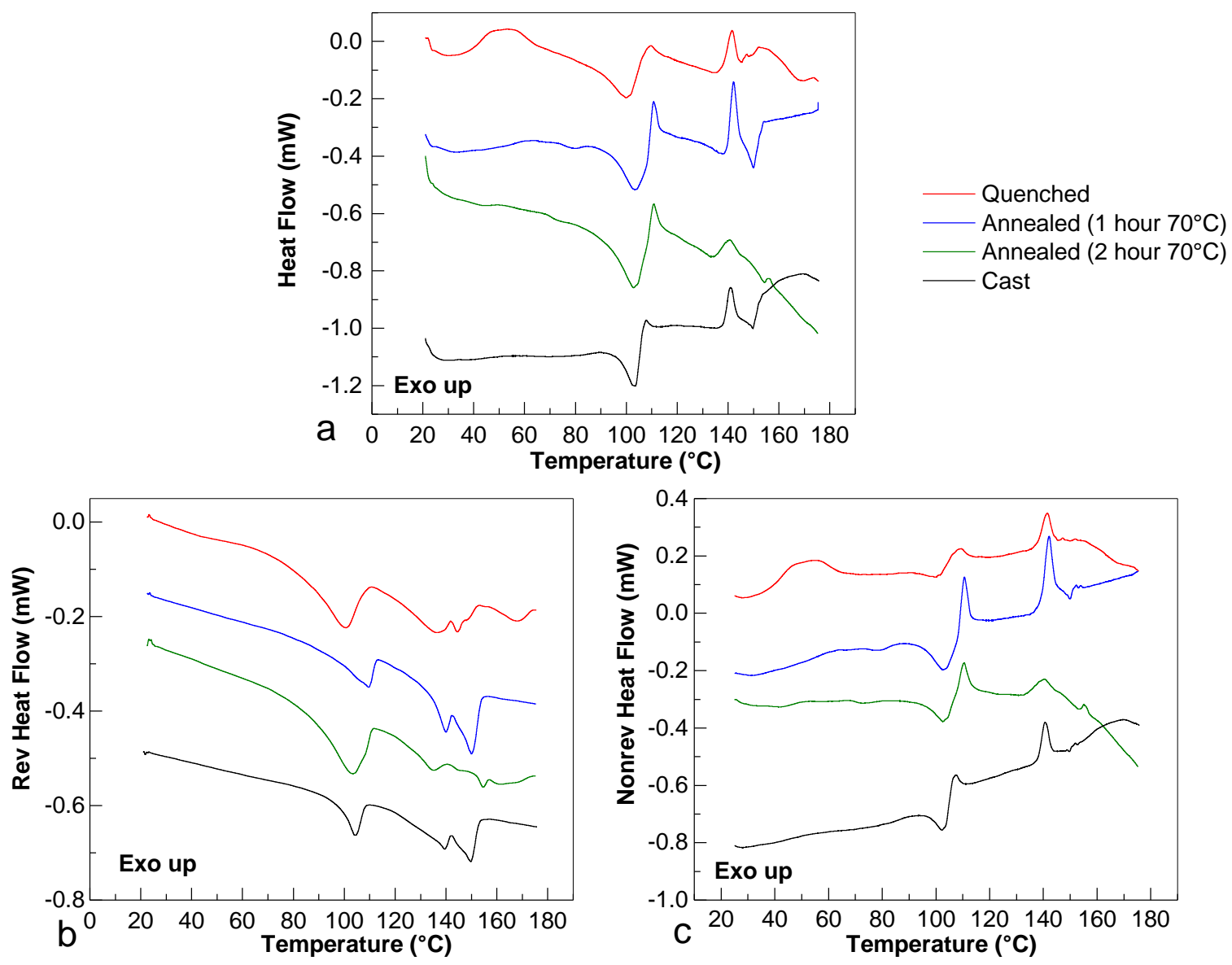

Figure 7. Total (a), reversible (b) and non-reversible (c) MDSC data for quenched, cast and annealed polyurethane 1 at a heating rate of $2{ }^{\circ} \mathrm{C} / \mathrm{min}$

The properties of polyurethanes are normally influenced significantly by micro-phase separation structures; ${ }^{21}$ therefore SAXS experiments have been performed in order to investigate the influence of the bisurethane end groups on the microphase separation in this material. Data from SAXS analysis of four specimens of polyurethane 1 with different processing histories (cast, quenched and annealed) are shown in Figure 8a. All three samples exhibit peaks that may be associated with microphase separation; however, whilst the profile for the cast materials possesses two peaks centred at $0.05 \AA^{-1}$ (d-spacing of $125 \AA$ ) and 0.105 $\AA^{-1}$ (60 $⿱$ ) ; after quenching, just one peak with a $d$-spacing of $60 \AA$ is observed. For the quenched then annealed specimens two peaks are again evident. This suggests the presence of lamellar ordering. To the best of our knowledge, this is the first report of a SAXS profile 
corresponding to a lamellar-type ordering in a supramolecular polyurethane of this type. However, broad maxima in the scattering profile of segmented polyurethanes has been previously reported, with a weak peaks at $80 \AA$ and another at $170 \AA$, and was attributed to a bimodal distribution of interdomain spacings. ${ }^{31}$
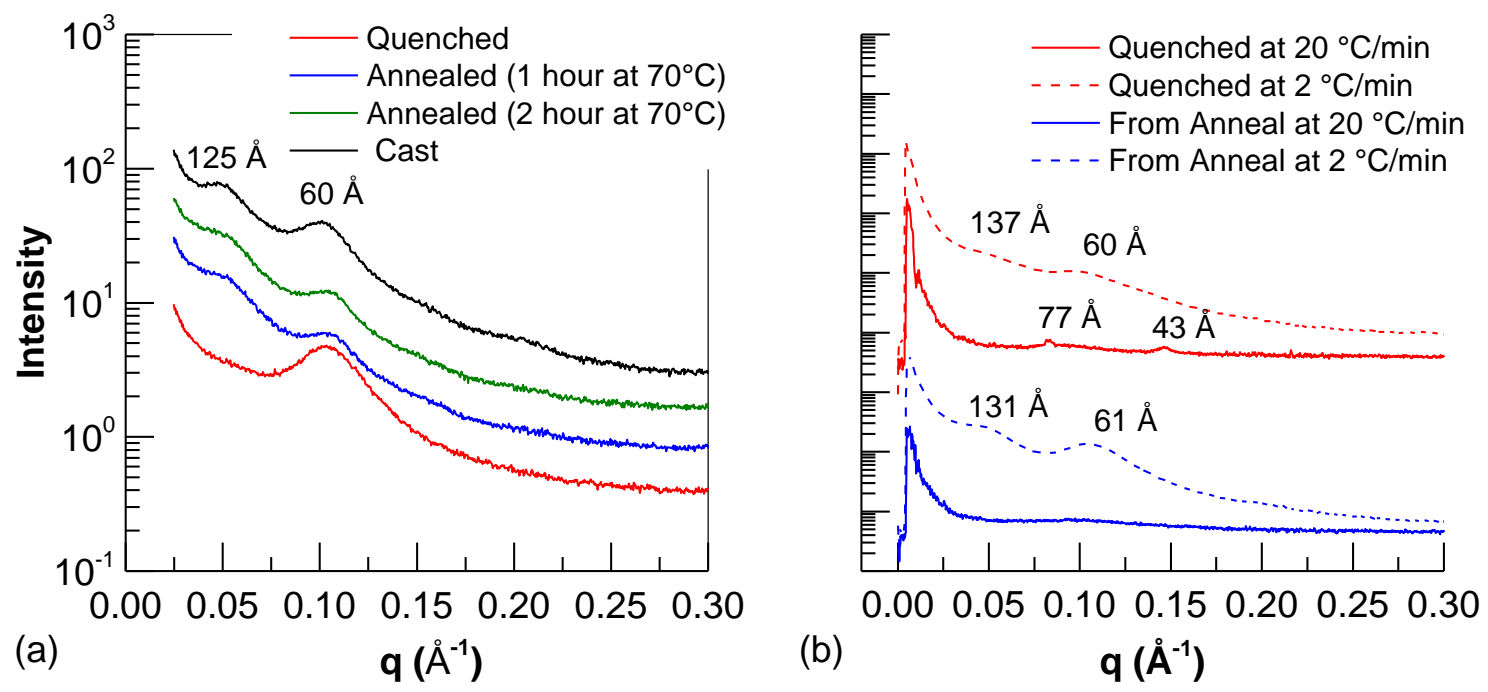

Figure 8. Small angle X-ray scattering (SAXS) of polyurethane 1 with; a) different processing histories, b) different cooling rates with respect to different processing histories (note that on this graph the results are stacked to allow better view of the curves)

Further SAXS experiments demonstrate the importance of heating and cooling rates on the structure of the polyurethane Figure $8 \mathrm{~b}$. It is shown that cooling from both annealing $\left(70{ }^{\circ} \mathrm{C}\right)$ and quenching $\left(180{ }^{\circ} \mathrm{C}\right)$ temperatures at rates $>15{ }^{\circ} \mathrm{C} / \mathrm{min}$ do not allow recovery of microphase separation. Interestingly some degree of ordering is apparent from the higher initial starting temperature (peaks appearing with a $d$-spacing of 77 and $43 \AA$ ), and a longer cooling time period allowing some recovery. Similar SAXS patterns are obtained on cooling the annealed polymer at $2{ }^{\circ} \mathrm{C} / \mathrm{min}$, although microphase separated structures are not observed on cooling at $20^{\circ} \mathrm{C} / \mathrm{min}$ (Figure $8 \mathrm{~b}$ and Figure S12). These results, combined with additional SAXS measurements previously mentioned (Figures S7-9), suggest parallels between mechanical properties, structural ordering and processing variations. 


\section{Discussion of mechanical and structural analysis}

The mechanical and structural date above indicate a rich spectrum of behaviours, which are consistent with a range of structural changes. In previous reports, SAXS domain spacing ranging from 40 to $80 \AA$ have been observed in similar bisurethane and bisurea systems..$^{10}$ In this study, lamellar ordering is observed for polyurethane 1 samples cast from a hot solution or obtained from an annealed melt, whilst the SAXS profile for the quenched sample lacks the low $q$ peak. Here the end-group has two rigid aromatic rings, and therefore, it is possible that it can adopt a more extended configuration permitted by stacking of the MDI units and urethane moieties, and thus the micro-phase separation of the supramolecular derivatives should favour alignment of the these moieties. The additional micro-phase structure (lamellar with $d$-spacing $=12.5 \mathrm{~nm}$ ) shows strong pathway dependence: it exists in cast polyurethane $\mathbf{1}$, can be removed by quenching from the melt, and then is regained by annealing. The formation of this additional micro-phase structure is thought to be the reason behind the timedependent increase of storage modulus above $65^{\circ} \mathrm{C}$, observed during the heating of quenched specimens, and the dramatic difference between the tensile behaviour of the quenched material on the one hand, and the cast or annealed materials, on the other. In particular, the increase in modulus and strength, accompanied by a decrease in strain to failure, can be explained by the development of lamellar ordering on heating. This is very unusual for a (block) copolymer system ${ }^{32}$ but can be rationalised in the present segemented polyurethane polymer if the hydrogen bonding network is disrupted at higher temperature giving rise to $\operatorname{LCST}^{33}$ (lower critical solution temperature) or LCOT (lower critical ordering transition) phase behaviour, i.e. microphase separation on heating. ${ }^{34}$ The disruption of the hydrogen bonding network is indicated by the VT-FTIR spectroscopic data discussed above. The lamellar spacing from the peaks in the SAXS profile, $12.5 \mathrm{~nm}$, is significantly larger than the estimated radius of gyration $\mathrm{R}_{\mathrm{g}}$ for this polymer, $c a .4 \mathrm{~nm}$, based on a degree of 
polymerization $N=130$ and a segment length $b=0.80 \mathrm{~nm}$ for poly(ethylene-co-butylene). ${ }^{35}$ This indicates significant chain extension in the lamellar state.

Considering the DSC data, the first exothermic peak $\left(\sim 50{ }^{\circ} \mathrm{C}\right)$ observed in the MDSC for quenched polyurethane $\mathbf{1}$ during heating is a result of the formation of the additional microphase suggested by the SAXS profile. Since quenching from the molten state does not allow the polymer chains enough time to self-assemble, the less thermodynamically favoured state is therefore trapped; however, thermal annealing allows the more thermodynamically favoured structures to form, causing the structural and mechanical changes observed in the rheometer experiments during heating. This is quite similar to other reported pathway dependent supramolecular polymers. ${ }^{26,36}$ For annealed polyurethane $\mathbf{1}$, it is consistent to observe the disappearance of the first exothermic peaks after annealing at $70{ }^{\circ} \mathrm{C}$ for two hours, since the annealing has already turned the quenched polyurethane $\mathbf{1}$ into the more stable thermodynamically favoured state, and thus the heating during analysis will not cause significant structural changes; this is again consistent with the mechanical response.

As the temperature is further increased, the first endothermic transition at about $100{ }^{\circ} \mathrm{C}$ and second endothermic transition at about $135^{\circ} \mathrm{C}$ are due to the disruption of the ordered microphase structures caused by the weakening of hydrogen bonds; the FTIR spectroscopic data show that these bonds start to disrupt at a temperature of $90^{\circ} \mathrm{C}$, at $130{ }^{\circ} \mathrm{C}$ the peak at 1740 $\mathrm{cm}^{-1}$ characteristic of unbound urethanes is as intense as the peak at $1705 \mathrm{~cm}^{-1}$ characteristic of bound urethanes, and finally, the hydrogen bond interactions are disrupted completely at $150{ }^{\circ} \mathrm{C}$. This can also explain the first and second sharp drop of the storage modulus starting at the temperatures of about 90 and $130{ }^{\circ} \mathrm{C}$, for cast polyurethane $\mathbf{1}$. There is no evidence of degradation in the mechanical performance after cycles of melting and quenching, and TGA analysis indicates the onset of degradation to be greater than $175{ }^{\circ} \mathrm{C}$, see Figure $\mathrm{S} 13$ in the ESM. The other two exothermic peaks observed by MDSC at the temperatures of 110 and 
$140{ }^{\circ} \mathrm{C}$ indicate that formation of ordered structures can occur at high temperatures, which may account for the two increases in the storage modulus associated with the large drops in quenched polyurethane $\mathbf{1}$.

When considering these results, and future applications of the material, it should be noted that the microstructure of the material would be expected to evolve at room temperature, perhaps on timescales of order weeks or months. ${ }^{37,38}$ In all the experiments reported here, structural or mechanical characterisation took place within at most a few hours of the thermal treatments; however, further research would be required to assess the long-term stability of the structure.

It is also interesting to compare this polyurethane with another thermoreversible supramolecular polyurethane we published $^{7}$ recently, which exhibited excellent healing properties with full recovery of the mechanical performance at $45^{\circ} \mathrm{C}$. There is only a small difference in the chemical structure of the phenyl end-groups. No additional micro-phase was observed in the case of that material, which demonstrates that even small end-group modifications can affect the self-assembly of supramolecular polyurethanes significantly, and thus leads to dramatically different behaviours and mechanical properties. From an application standpoint, it is also useful to note that polyurethane 1, especially in the annealed state, retains its high modulus to a higher temperature than the other material, giving a wider range of potential applications.

\section{Adhesion properties}

The desirable properties of inherent good processability and large scale tunable mechanical properties make polyurethane $\mathbf{1}$ a good candidate for use as an adhesive and coating material, and further characterisation was performed through peel and tack testing. Peel testing and 
subsequent data analysis follows the procedures outlined in the ESIS TC4 protocol, described in the ESM, for the determination of the adhesive fracture energy for flexible laminates using peel tests. ${ }^{39}$ Representative load vs. displacement curves are shown in ESM (Figure S16), and the calculated data can be seen in Tables S1 and S2, also in the ESM. It is observed that the peel strength does not depend significantly on specimen preparation temperature, and excellent adhesion properties can be achieved for specimens prepared at ambient temperature $\left(25^{\circ} \mathrm{C}\right)$ using quenched polyurethane 1 , with a calculated adhesive fracture energy as high as $740 \mathrm{~J} \mathrm{~m}^{-2}$. However, annealing at a temperature of $70{ }^{\circ} \mathrm{C}$ for two hours, which increases the strength, but reduces the ductility of the polyurethane film, leads to a much lower peel strength, with a calculated adhesive fracture energy of $120 \mathrm{~J} \mathrm{~m}^{-2}$. It should be noted that the adhesive fracture energy calculated by the peel test is the practical adhesion of the materials, which includes two parts: one is the energy consumed by the separation of polyurethane $\mathbf{1}$ film and substrate, the other is the energy consumed due to the large deformation of polyurethane 1 film itself. Therefore, the test results can be explained by the different failure behaviour of the peel joints, as shown in Figure S17. It is observed that quenched polyurethane 1 presents cohesive failure, the film experiences large deformation before failure, which consumes significant energy, and thus shows high fracture adhesive energy owing to the soft, weak but flexible nature of the material. However, after two hours annealing at the temperature of $70{ }^{\circ} \mathrm{C}$, the film is much stiffer and stronger, but brittle. Thus, failure does not occur within the film, but from the interface between film and substrate, and the deformations are smaller, Figure S17b.

Two further observations can be made regarding these experiments. Firstly, that it was not possible to produce reliable peel specimens by solution casting of the material, which is consistent with the discussion in this section, and the tensile data obtained above. Secondly, that when peel specimens were produced at $50^{\circ} \mathrm{C}$ from the quenched material, it was found 
that the peel test data were less reliable (see Figure S16), than those from specimens produced at $25{ }^{\circ} \mathrm{C}$ and $35^{\circ} \mathrm{C}$. This is consistent with there being some evolution of the structure at $50{ }^{\circ} \mathrm{C}$, if not as much as would take place at $70{ }^{\circ} \mathrm{C}$.

Tack tests were performed at three different normal forces for quenched polyurethane $\mathbf{1}$ at room temperature $\left(20^{\circ} \mathrm{C}\right)$; the results are presented in Figure 9. It is observed that the stresstime curves show a plateau in stress following the initial peak, and the peak stress shows pressure dependence, which increases with increasing normal force. This is consistent with the behaviour of a classic pressure sensitive adhesive (PSA). A peak stress as high as 1.2 MPa is reached at the normal force of $20 \mathrm{~N}$, which is close to the value of standard PSA, ${ }^{40}$ and suggests that quenched polyurethane $\mathbf{1}$ can be used as a PSA. It is not possible to use the cast polyurethane $\mathbf{1}$ as a PSA at ambient temperature as it is a solid with shear modulus of approximately $20 \mathrm{MPa}$; however, thermal treatment by quenching to avoid the thermodynamically favoured state, once again demonstrates the functional potential of such supramolecular polymers by utilising their unique pathway dependence.

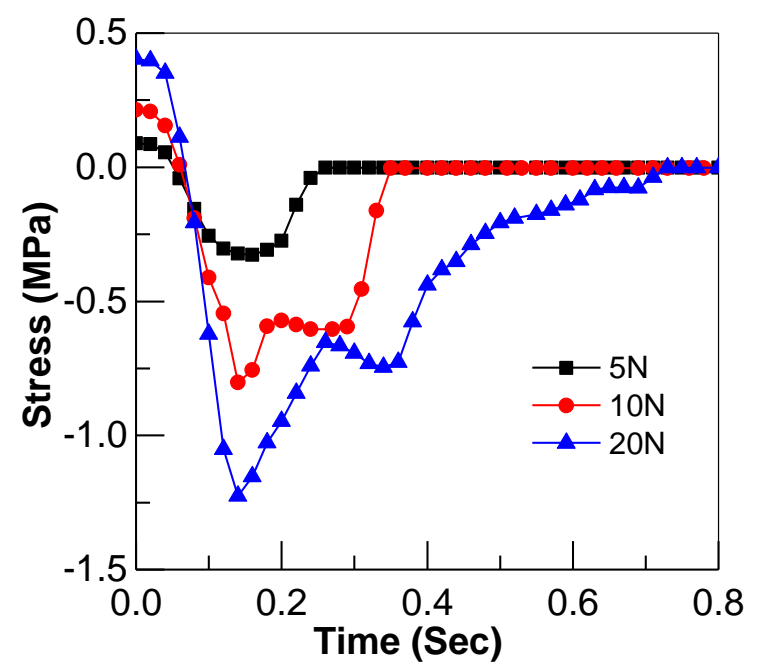

Figure 9. Stress $v s$. time curves for quenched polyurethane $\mathbf{1}$ from probe tack tests with different normal forces at a temperature of $20^{\circ} \mathrm{C}$ and speed of $-5 \mathrm{~mm} / \mathrm{s}$. 


\section{Conclusion}

In this work, a novel kinetically controlled, thermoreversible supramolecular polyurethane with high dependence on processing history was synthesised. The data presented indicate that the degree of microphase separation in this material can be controlled by different processing conditions, giving rise to different rheological and mechanical properties. This, in addition to the rapid decrease in modulus above certain temperatures, endows polyurethane $\mathbf{1}$ with inherently good processability and tunable large-scale mechanical behaviour that can be modified by simple thermal treatments.

More specifically, whilst solution casting produces relatively stiff, strong and brittle specimens, quenching from the melt produces a soft, flexible material with a large strain to failure. Subsequent annealing of the quenched material returns it to mechanical properties similar to the cast state, but with increased strain to failure. Comprehensive structural characterisation has produced results consistent with the mechanical response. MDSC showed that there are multiple transitions during heating, which are the cause of the complex rheological behaviour. VT-FTIR spectroscopic studies showed that the hydrogen bonds start to disrupt from $90^{\circ} \mathrm{C}$ until $150^{\circ} \mathrm{C}$. SAXS suggests the presence of a lamellar structure at high temperature, which to our knowledge is an unprecedented observation for this type of supramolecular polymer system. This microphase existed in the cast polyurethane $\mathbf{1}$ and could be destroyed by quenching, but was then regained by annealing at a suitable temperature: it is the primary cause of the unique pathway dependence for this material. The unique properties of polyurethane $\mathbf{1}$ make it a candidate for use as a smart material for adhesives and coatings. Peel tests showed that excellent fracture adhesive energy can be obtained for the quenched polyurethane $\mathbf{1}$ prepared at ambient temperature, and tack tests showed that the quenched material $\mathbf{1}$ has potential for use as a PSA; however, further research would be need to assess effect of long term structural evolution on these properties. 


\section{Acknowledgements}

This work was supported by EPSRC [EP/J010715/1 and EP/J011436/1] and ESRF [beamtime ref. SC-4311] on BM26B (DUBBLE).

We are grateful to the University of Reading for access to instrumentation in the Chemical Analysis Facility, to Mr Nick Spencer for assistance with SAXS/WAXS, and Cray Valley for the supply of $\mathrm{Krasol}^{\mathrm{TM}}$ HLBH-P2000. CRS and XT would like to thank Richard Duffin, Richard Froud, Neil Warland, and Igor Dyson for technical support at Oxford University.

Electronic Supplementary Material is available from the authors or the journal website: synthesis and experimental details, FTIR and SAXS data, additional rheometry and stressstrain profiles and peel test details

\section{References}

1. Cordier, P.; Tournilhac, F.; Soulié-Ziakovic, C.; Leibler, L. Self-healing and thermoreversible rubber from supramolecular assembly. Nature 2008, 451, 977-980.

2. Bosman, A. W.; Sijbesma, R. P.; Meijer, E.W. Supramolecular polymers at work. Materials Today 2004, 7, 34-39.

3. de Greef, T.F.A.; Meijer, E.W. Supramolecular Polymers Foreword. Aust. J. Chem. 2010, 63, 596-598.

4. de Greef, T.F.A.; Smulders, M.M. J.; Wolffs, M.; Schenning, A. P. H. J.; Sijbesma, R. P.; Meijer, E.W. Supramolecular Polymerization. Chem. Rev. 2009, 109, 5687-5754.

5. Burattini, S.; Greenland, B. W.; Chappell, D.; Colquhoun, H. M.; Hayes, W. Healable polymeric materials: a tutorial review. Chem. Soc. Rev. 2010, 39, 1973-1985.

6. Fox, J.; Rowan, S. J. Supramolecular Polymerizations and Main-Chain Supramolecular Polymers. Macromolecules 2009, 42, 6823-6835. 
7. Feula, A.; Pethybridge, A.; Tang, X.G.; Chippindale, A.; Siviour, C. R.; Buckley, C. P.; Hamley, I. W.; Hayes, W. A Thermoreversible Supramolecular Polyurethane with Excellent Healing Ability at 45 degrees C. Macromolecules 2015, 48, 6132-6141.

8. Kuo, M-C.; Jeng, R-J.; Su, W-C.; and Dai S.A.; Iterative Synthesis of Extenders of Uniform Chain Lengths for Making Thermo-reversible Polyurethane Supramolecules Macromolecules 2008, 41, 682-690

9. Aida, T.; Meijer E. W.; Stupp, S. I. Functional Supramolecular Polymers. Science 2012, $335,813-817$.

10. Merino, D. H.; Slark, A. T.; Colquhoun, H. M.; Hayes, W.; Hamley, I. W. Thermoresponsive microphase separated supramolecular polyurethanes. Polym. Chem. 2010, 1, $1263-1271$

11 Liow, S.S.; Lipik, V.T; Widjaja, L.K; Venkatraman, S.S.; Abadie, M.J.M.; Enhancing mechanical properties of thermoplastic polyurethane elastomers with 1,3-trimethylene carbonate, epsilon-caprolactone and L-lactide copolymers via soft segment crystallization. eXPRESS Polymer Letters 2011, 5, 897-910

12. Woodward, P. J.; Merino, D. H.; Greenland, B. W.; Hamley, I. W.; Light, Z.; Slark, A. T.; Hayes, W. Hydrogen Bonded Supramolecular Elastomers: Correlating Hydrogen Bonding Strength with Morphology and Rheology. Macromolecules 2010, 43, 2512-2517.

13. Matos-Pérez, C. R.; White, J. D.; Wilker, J. J. Polymer Composition and Substrate Influences on the Adhesive Bonding of a Biomimetic, Cross-Linking Polymer. J. Am. Chem. Soc. 2012, 134, 9498-9505.

14. Behl, M.; Lendlein, A. Shape-memory polymers. Materials Today, 2007, 10, 20-28. 
15. Houton, K. A.; Wilson, A. J. Hydrogen-bonded supramolecular polyurethanes. Polym. Int. 2015, 64, 165-173.

16. Burattini, S.; Greenland, B. W.; Merino, D. H.; Weng, W.G.; Seppala, J.; Colquhoun, H. M.; Hayes, W.; Mackay, M. E.; Hamley, I. W.; Rowan, S. J. A Healable Supramolecular Polymer Blend Based on Aromatic pi-pi Stacking and Hydrogen-Bonding Interactions. J. Am. Chem. Soc. 2010, 132, 12051-12058.

17. Mir, I.; Kumar, D. Recent advances in isotropic conductive adhesives for electronics packaging applications. Int. J. Adhes. Adhes. 2008, 28, 362-371.

18. Mattia, E.; Otto, S. Supramolecular systems chemistry. Nature Nanotech. 2015, 10, 111119.

19. Hutin, M.; Burakowska-Meise, E.; Appel, W. P. J.; Dankers; P. Y. W.; Meijer, E. W. From Molecular Structure to Macromolecular Organization: Keys to Design Supramolecular Biomaterials. Macromolecules 2013, 46, 8528-8537

20. Hagan, M. F.; Elrad, O. M.; Jack, R. L. Mechanisms of kinetic trapping in self-assembly and phase transformation, J. Chem. Phys. 2011, 135, 104115.

21. He, Y.; Xie, D. L.; Zhang, X. Y. The structure, microphase-separated morphology, and property of polyurethanes and polyureas. J. Mater. Sci. 2014, 49, 7339-7352.

22. Anokhin, D. V.; Gorbunova, M. A.; Estrin, Y. I.; Komratova, V. V.; Badamshina, E. R. The role of fast and slow processes in the formation of structure and properties of thermoplastic polyurethanes. Phys. Chem. Chem. Phys. 2016, 18, 31769-31776.

23. Aida, T.; Meijer, E.W.; Stupp, S. I. Functional supramolecular polymers. Science 2012, $335,813-817$. 
24. Wang, A.D.; Shi, W.Y.; Huang, J.B.; Yan, Y. Adaptive soft molecular self-assemblies. Soft Matter 2016, 12, 337-357.

25. Yan, Y.; Huang, J.; Tang, B.Z. Kinetic trapping - a strategy for directing the selfassembly of unique functional nanostructures. Chem. Commun. 2016, 52, 11870-11884.

26. de Greef, T.F.A.; Meijer, E.W. Materials science: Supramolecular polymers. Nature, 2008, 453, 171-173.

27. Feula, A.; Tang, X.G.; Giannakopoulos, I.; Chippindale, A. M.; Hamley, I. W.; Greco, F.; Buckley, C. P.; Siviour, C. R.; Hayes, W. An adhesive elastomeric supramolecular polyurethane healable at body temperature. Chem. Sci. 2016, 7, 4291-4300.

28. Woodward, P.; Merino, D. H.; Hamley, I. W.; Slark, A. T.; Hayes, W. Thermally Responsive Elastomeric Supramolecular Polymers Featuring Flexible Aliphatic HydrogenBonding End-Groups. Aust. J. Chem. 2009, 62, 790-793.

29. Royall, P.G.; Craig, D. Q. M.; Doherty, C. Characterisation of the glass transition of an amorphous drug using modulated DSC. Pharm. Res.1998, 15, 1117-1121.

30. Sauer, B.B.; Kampert, W.G.; Blanchard, E. N.; Threefoot, S. A.; Hsiao, B. S. Temperature modulated DSC studies of melting and recrystallization in polymers exhibiting multiple endotherms. Polymer 2000, 41, 1099-1108.

31. Koberstein, J. T.; Stein, R. S. Small-Angle X-ray Scatting Studies of Microdomain Structure in Segmented Polyurethane Elastomers. J. Polym. Sci. Pol. Phys. 1983, 21, 14391472.

32. Hamley, I.W. The Physics of Block Copolymers, OUP, Oxford, UK, 1998.

33. Koningsveld, R.; Stockmayer, W. H.; Nies, E. Polymer Phase Diagrams, OUP, Oxford, UK, 2001. 
34. Russell, T.P.; Karis, T.E.; Gallot, Y.; Mayes, A.M. A lower critical ordering transition in a diblock copolymer melt. Nature 1994, 368, $729-731$.

35. Fetters, L. J.; Lohse, D. J.; Richter, D.; Witten, T. A.; Zirkel, A. Connection between Polymer Molecular Weight, Density, Chain Dimensions, and Melt Viscoelastic Properties. Macromolecules, 1994, 27, 4639-4647.

36. Korevaar, P. A.; George, S. J.; Markvoort, A. J.; Smulders, M. M. J.; Hilbers, P. A. J.; Schenning, A. P. H. J.; De Greef, T. F. A. Pathway complexity in supramolecular polymerization. Nature 2012, 481, 492-496.

37 Anokhin, D. V.; Gorbunova, M. A.; Estrin, Y. I.; Komratova, V. V.; Badamshina, E. R. The role of fast and slow processes in the formation of structure and properties of thermoplastic polyurethanes Phys.Chem.Chem.Phys., 2016, 18, 31769-31776

38 Li, X. K.; Stribeck, A.; Schulz, I.; Poselt, E.; Eling, B.; Hoell, A. Nanostructure of thermally aged thermoplastic polyurethane and its evolution under strain European Polymer Journal 2016, 81, 569-581

39. Moore, D.R.; Williams, J.G. A protocol for determination of the adhesive fracture toughness by peel testing of flexible laminates http://www3.imperial.ac.uk/meadhesion/testprotocols/peel accessed 13 October 2015.

40. Courtois, J.; Baroudi, I.; Nouvel, N.; Degrandi, E.; Pensec, S.; Ducouret, G.; Chane’ac, C.; Bouteiller, L.; Creton, C. Supramolecular Soft Adhesive Materials. Adv. Funct. Mater. 2010, 20, 1803-1811. 